\title{
POTENSI AIRTANAH STATIS \\ DI DAERAH TANGKAPAN AIR GOA PINDUL \\ KABUPATEN GUNUNGKIDUL
}

\author{
Slamet Suprayogi ${ }^{1}$, Setyawan Purnama ${ }^{2}$, Romza Fauzan Agniy ${ }^{3}$ dan Ahmad Cahyadi ${ }^{4}$

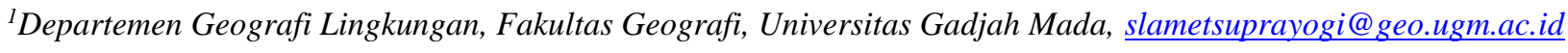 \\ ${ }^{2}$ Departemen Geografi Lingkungan, Fakultas Geografi, Universitas Gadjah Mada, setyapurna@gmail.com \\ ${ }^{3}$ Departemen Geografi Lingkungan, Fakultas Geografi, Universitas Gadjah Mada, romza.fauzan.a@mail.ugm.ac.id \\ ${ }^{4}$ Departemen Geografi Lingkungan, Fakultas Geografi, Universitas Gadjah Mada, ahmadcahyadi@geo.ugm.ac.id
}

\begin{abstract}
ABSTRAK
Perkembangan wisata di kawasan Goa Pindul dan Sekitarnya memiliki konsekuensi di antaranya adalah kebutuhan akan sumberdaya air yang semakin banyak. Salah satu sumberdaya yang banyak dimanfaatkan di lokasi kajian adalah airtanah. Penelitian ini bertujuan untuk melakukan analisis potensi airtanah statis di lokasi kajian. Data yang dibutuhkan meliputi luas wilayah kajian, kondisi akuifer dan nilai specific yield akuifer. Luas wilayah kajian ditentukan berdasarkan hasil penelitian sebelumnya. Kondisi akuifer ditentukan berdasarkan pada data log bor di lokasi kajian. Nilai specific yield ditentukan dengan analisis ketetapan pada referensi dan rekonstruksi data log bor. Hasil perhitungan menunjukkan bahwa potensi airtanah pada akuifer bagian atas adalah sejumlah $24.642 .000 \mathrm{~m}^{3}$, sedangkan pada akuifer bagian bawah memiliki potensi airtanah statis sebesar $134.162 .000 \mathrm{~m}^{3}$.
\end{abstract}

Kata Kunci: Potensi, Airtanah, Goa Pindul, Gunungkidul

\section{Pendahuluan}

Perkembangan pariwisata di Goa Pindul, Kecamatan Karangmojo, Kabupaten Gunungkidul, Daerah Istimewa Yogyakarta saat ini cukup signifikan [1]. Peningkatan jumlah pengunjung setiap tahunnya tentunya memberikan dampak yang besar bagi pendapatan masyarakat, baik yang tergabung langsung sebagai pengelola, operator ataupun penyedia jasa dan pelaku aktivitas perdagangan [2, 3]. Hal ini menyebabkan Goa Pindul menjadi ikon baru wisata di Kabupaten Gunungkidul yang sebelumnya selalu hanya didominasi oleh wisata pantai.

Pertambahan jumlah wisatawan secara tidak langsung akan menyebabkan bertambahnya kebutuhan akan air, khususnya terkait dengan konsumsi dan aktivitas pendukung pariwisata. Goa pindul yang merupakan sungai bawah tanah tentunya tidak akan mengalami permasalahan terkait ketersediaan air untuk keperluan wahana air. Namun demikian, untuk mencukupi kebutuhan air bersih maka diperlukan sumber air yang lain agar terpenuhi secara kualitas.

Daerah tangkapan air Goa Pindul memiliki luas 15,44 $\mathrm{km}^{2}$ (Gambar 1) [4]. Daerah tangkapan air Goa pindul secara garis besar terdiri atas dua sistem hidrogeologi, yakni sistem di bagian hulu yang didominasi aliran diffuse (aliran airtanah melalui rongga antar butir batuan $[5,6]$ ) dan sistem di bagian hilir yang didominasi oleh aliran konduit (aliran airtanah yang didominasi oleh aliran melalui lorong-lorong pelarutan $[5,6])$ (Gambar 2). Luas sistem diffuse adalah 13,69 $\mathrm{km}^{2}$, sedangkan luas sistem konduit adalah seluas $1,75 \mathrm{~km}^{2}[4]$. 


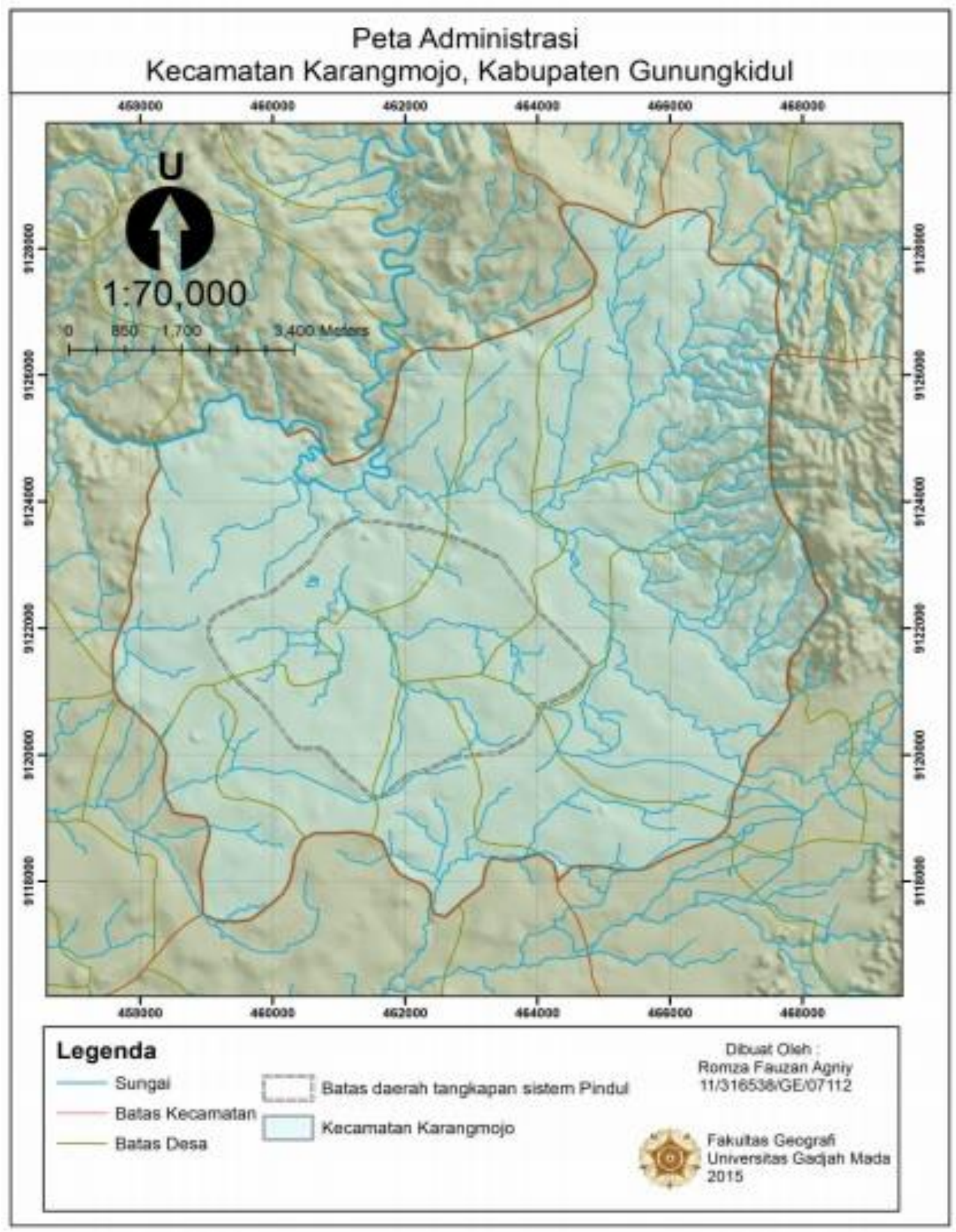

Gambar 1. Lokasi Daerah Tangkapan Air Goa Pindul di Kecamatan Karangmojo, Kabupaten Gunungkidul [4] 


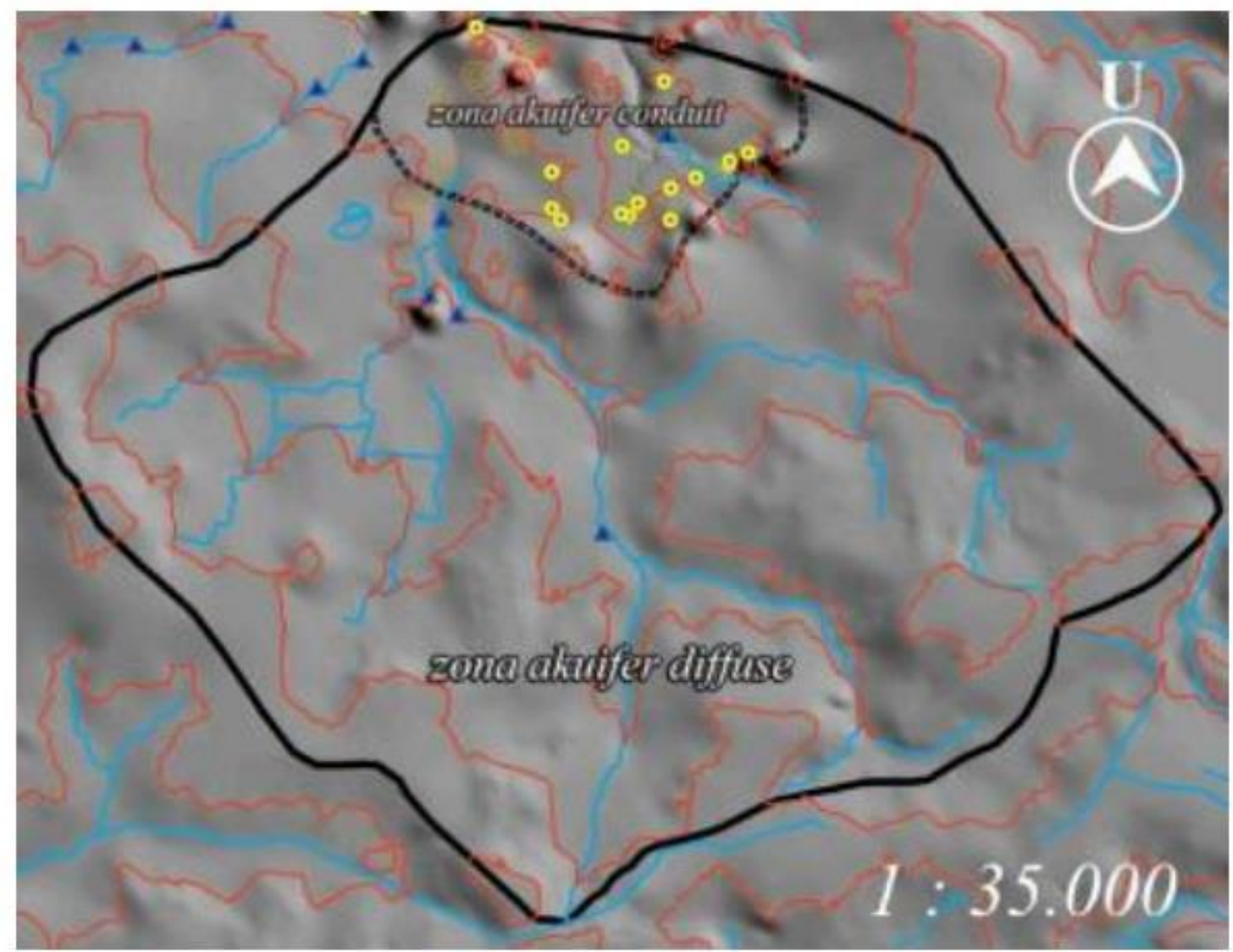

Gambar 2. Pembagian Sistem Hidrogeologi daerah Tangkapan Air Goa Pindul [4]

Airtanah di kawasan sistem hidrogeologi konduit sebenarnya cukup melimpah, namun demikian air pada sungai bawah tanah utama memiliki kualitas air yang kurang baik. Hanya sedikit air dari sistem ini yang memiliki kualitas yang baik misalnya pada Mataair Ngancar. Namun demikian, ketika terjadi hujan atau saat musim penghujan kualitas air akan menjadi buruk. Kondisi ini disebabkan karena sungai bawah tanah di lokasi ini terhubung secara langsung dengan aliran permukaan melalui sinkhole, ponor dan sinkingstream $[7,8]$. Hal ini menyebabkan pencemar yang terbawa aliran permukaan akan masuk secara langsung ketika terjadi hujan. Oleh karena itu, maka airtanah pada sistem aliran diffuse di bagian hulu menjadi sumber utama bagi penyediaan air di Kawasan Karst Goa Pindul.

Airtanah pada sistem diffuse dapat dimanfaatkan melalui mataair dan sumur. Mataair ini muncul sebagai akibat perbindahan formasi dari gamping yang tidak berkembang baik ke arah gamping yang berkembang baik. Kontak formasi inilah yang menyebabkan munculnya mataair. Meskipun demikian, debit yang kurang besar dari mataair ini Prosiding Seminar Nasional Geografi Lingkungan I, 27 November 2016 di Fakultas Geografi UGM Yogyakarta. Halaman 86 - 91. ISBN 978-979-8786-65-5 menyebakan pemanfaatan untuk memenuhi kebutuhan air di kawasan wisata Goa Pindul akan menemui banyak kendala terkait dengan konflik kepentingan. Hal ini karena kebanyakan mataair telah digunakan untuk sector lain seperti domestic, pertanian, dan perikanan. Oleh karena itu, maka pengambilan melalui sumur gali pada akuifer di sistem aliran diffuse dapat menjadi pilihan.

Airtanah seringkali menjadi sumber utama untuk memenuhi kebutuhan air bersih karena biasanya memiliki kualitas yang lebih baik dibandingkan dengan air permukaan $[9,10]$. Namun demikian, pemanfaatan yang tidak mempertimbangkan ketersediaannya di alam akan menyebabkan terjadinya kerusakan lingkungan seperti semakin dalamnya muka airtanah dan penurunan muka tanah. Oleh karena itu, maka kajian terkait dengan ketersediaan airtanah menjadi sangat penting. Penelitian ini bertujuan untuk menganalisis kuantitas airtanah statis di daerah tangkapan air sistem Goa Pindul, Kecamatan Karangmojo, Kabupaten Gunungkidul. 


\section{Metode Penelitian}

Perhitungan potensi airtanah statis dilakukan dengan persamaan 1.

$$
\mathbf{H}=\mathbf{A} \text {. Da } . \text { Sy }
$$

\section{Keterangan:}

$\mathrm{H}=$ Ketersediaan airtanah $\left(\mathrm{m}^{3}\right)$;

A = Luas zona potensi airtanah $\left(\mathrm{m}^{2}\right)$;

$\mathrm{Da}=$ Ketebalan rerata akuifer $(\mathrm{m})$;

Sy $=$ Hasil jenis $(\%)$

Ketersediaan airtanah yang dimaksud dalam penelitian ini dibatasi pada potensi airtanah statis. Luas zona potensi airtanah yang dimaksud dalam persamaan 1 adalah luas daerah tangkapan air sistem Goa Pindul yang berupa sistem diffuse. Data ini didasarkan pada Gambar 2 di atas. Data ketebalan akuifer dianalisis berdasarkan pada data log bor. Data log bor diperoleh dari data sekunder dari Dinas Pekerjaan Umum dan Energi Sumberdaya Mineral (PUESDM) Daerah Istimewa Yogyakarta. Data log bor yang digunakan sejumlah tiga titik, yang kesemuanya terletak di dalam daerah tangkapan air sistem Goa Pindul. Data hasil jenis (specific yield) didasarkan pada data hasil rekonstruksi data log bor dan Tabel 1.

Tabel 1. Nilai Spesific Yield pada Beberapa Material []

\begin{tabular}{|l|c|l|c|}
\hline \multicolumn{1}{|c|}{ Material } & Specific Yield (\%) & \multicolumn{1}{c|}{ Material } & Specific Yield (\%) \\
\hline Gravel, coarse & 23 & Limestone & 14 \\
\hline Gravel, medium & 24 & Sand Dune & 38 \\
\hline Gravel. Fine & 25 & Loess & 18 \\
\hline Sand, coarse & 27 & Peat & 26 \\
\hline Sand, medium & 28 & Schist & 12 \\
\hline Sand, fine & 23 & Siltstone & 6 \\
\hline Silt & 8 & Till, predominantly silt & 16 \\
\hline Clay & 3 & Till, predominantly sand & 16 \\
\hline Sandstone, fine-grained & 21 & Till, predominantly gravel & 21 \\
\hline Sandstone, medium-grained & 27 & Tuff & \\
\hline
\end{tabular}

\section{Hasil dan Pembahasan}

Hasil rekonstruksi tiga data log bor yang terdapat di lokasi kajian ditunjukkan pada Gambar 3. Hasil rekonstruksi menunjukkan bahwa setidaknya material akuifer di lokasi kajian dapat dibagi menjadi dua, yaitu akuifer dengan material penyusun lempung yang terletak di bagian atas dan akuifer dengan material penyusun batu gamping. Ketebalan lempung yang teridentifikasi adalah antara 40 meter sampai dengan 80 meter, dengan ketebalan rata-rata adalah 60 meter. Ketebalan batu gamping di lokasi kajian mulai dari 50 meter sampai dengan 90 meter, dengan rata-rata ketebalan 70 meter (berdasarkan data log bor dengan kedalaman maksimum 140 meter). 


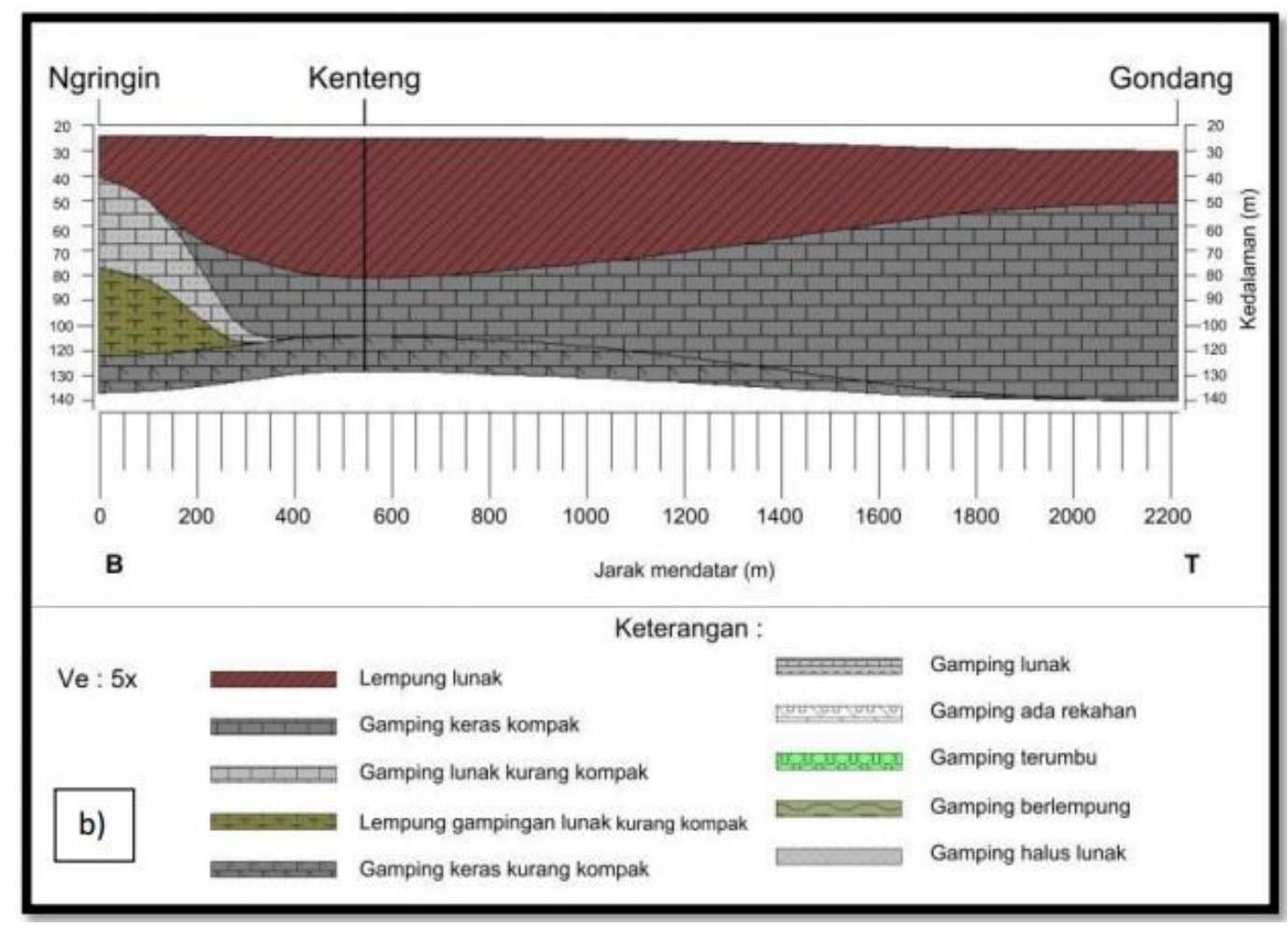

Gambar 3. Hasil Rekonstruksi Data Log Bor di Lokasi Kajian [4]

Berdasarkan hasil rekonstruksi pada Gambar 3, maka perhitungan potensi airtanah pada lokasi kajian juga dibagi menjadi dua. Pertama potensi airtanah di bagian atas yang didominasi material lempung dan kedua adalah bagian bawah akuifer yang didominasi material batu gamping. Hasil perhitungan menunjukkan bahwa potensi airtanah pada akuifer bagian atas adalah sejumlah 24.642.000 $\mathrm{m}^{3}$, sedangkan pada akuifer bagian bawah memiliki potensi airtanah statis sebesar $134.162 .000 \mathrm{~m}^{3}$. Besarnya nilai potensi airtanah pada akuifer di bagiuan bawah disebabkan karena ketebalan yang lebih besar dan nilai specific yield yang lebih besar. Nilai Spesific Yield lempung adalah sebesar 3\%, sedangkan nilai specific Yield batu gamping adalah sebesar $14 \%$ atau nyaris lima kali lipat dari lempung.

Karakteristik akuifer di lokasi kajian dengan lapisan lempung di bagian atas yang tebal menimbulkan masalah tersendiri dalam pengelolaan airtanah $[10,11,12]$. Kapasitas infiltrasi yang rendah akan menyebabkan imbuhan airtanah di wilayah ini menjadi sangat sedikit. Hal ini beraki- bat pengambilan airtanah di bagian atas akuifer akan menyebabkan kerusakan sumberdaya airtanah dan lahan [11]. Pengambilan airtanah dengan jumlah yang cukup besar disarankan dilakukan pada kedalaman lebih dari 40 meter agar mengambil pada lapisan batu gamping. Selain itu, diperlukan usaha-usaha untuk memperbanyak artificial recharge $[11,12]$. Misalnya dengan pembuatan sumur resapan airtanah dalam, pembuatan embung, dan rorak dan kalenan di sekitar lahan pertanian.

\section{Kesimpulan}

Hasil perhitungan menunjukkan bahwa potensi airtanah pada akuifer bagian atas adalah sejumlah 24.642.000 $\mathrm{m}^{3}$, sedangkan pada akuifer bagian bawah memiliki potensi airtanah statis sebesar $134.162 .000 \mathrm{~m}^{3}$. Karakteristik akuifer dengan lapisan tanah atas berupa lempung menyebabkan pengambilan airtanah di kedalaman kurang dari 40 meter dapat menyebabkan terjadinya kerusakan lingkungan. Oleh karena itu, maka disarankan pengambilan airtanah dengan 
jumlah yang banyak dapat dilakukan pada kedalaman lebih dari 40 meter dengan dibarengi usaha-usaha penambahan imbuhan airtanah secara buatan.

\section{Pengakuan dan Ucapan Terimakasih}

Penelitian ini merupakan bagian dari hibah penelitian unggulan perguruan tinggi (PUPT) tahun 2016 yang berjudul "Karakterisasi Hidrologi dan Banjir di Sungai Bawah Tanah Goa Pindul untuk Mendukung Pengelolaan Pariwisata Berkelanjutan Berbasis Manajemen

Kebencanaan". Penelitian ini didanai oleh Direktorat Riset dan Pengabdian Masyarakat, Direktirat Jenderal Penguatan Riset dan Pengembangan, Kementerian Riset, Teknologi dan Pendidikan Tinggi sesuai Surat Perjanjian Penugasan Pelaksanaan Program Penelitian Nomor: 015/SP2H/LT/DPRM/II/2016 Tanggal 17 Februari 2016. Penulis mengucapkan terima kasih kepada semua pihak yang telah membantu terlaksananya penelitian ini.

\section{REFERENSI}

[1] Musadad. 2014. Partisipasi Masyarakat Dusun Gelaran II dalam Pengembangan Wisata di Goa Pindul, Kabupaten Gunungkidul. Thesis. Yogyakarta : Sekolah Pascasarjana Universitas Gadjah Mada.

[2] Fandeli, C. 2002. Perencanaan Kepariwisataan Alam. Yogyakarta : Fakultas Kehutanan Universitas Gadjah Mada.

[3] UNWTO 13th General Assembly. 1999. Global Code of Ethics for Tourism. Santiago: UNWTO. (http://www.unwto.org/code_ethics/eng/brochure.htm)
[4] Agniy, R.F. 2016. Kajian Hidrogeologi Karst Sistem Gua Pindul,Kecamatan Karangmojo, Kabupaten Gunungkidul. Skripsi. Yogyakarta: Fakultas Geografi Universitas Gadjah Mada.

[5] White, W.B., 1988. Geomorphology and Hydrology of Karst Terrain. New York: Oxford University Press.

[6] Cahyadi, A. 2014. Keunikan Hidrologi Kawasan Karst: Suatu Tinjauan, dalam Cahyadi, A.; Prabawa, B.A.; Tivianton, T.A. dan Nugraha, H. 2014. Ekologi Lingkungan Kawasan Karst Indonesia: Menjaga Asa Kelestarian Kawasan Karst Indonesia, Volume 2. Yogyakarta: Deepublish.

[7] Ford, D.C. dan William, P.W. 2007. Karst Geomorphology and Hydrology. Chicester : John Willey and Sons.

[8] Haryono, E. dan Tjahyo N.A. 2004. Geomorfologi dan Hidrologi Karst. Yogyakarta: Kelompok Studi Karst Fakultas Geografi UGM.

[9] Domenico, P.A. 1972. Concepts and Models in Groundwater Hydrology. New York: McGraw-Hill Book Company.

[10] Davis, S.N. dan De Wiest, R.J.M. 1966. Hydrogeology. New York: John Wiley and Sons.

[11] Todd, D.K. 1995. Groundwater Hydrology, Second Edition. Singapore: John Wiley and Sons.

[12] Simmers, I. 1988. Estimation of Natural Graoundwater Recharge. Dordrecht: D. Riedel Publishing Company. 